\title{
Nonsyndromic Split Hand/ Foot Malformation: Ectrodactyly
}

\author{
Ray $\mathbf{S}^{1}$, Jain $\mathbf{P C}^{2}$
}

${ }^{1}$ Dr. Ray Sanghamitra, MBBS. MD, ${ }^{2} \mathrm{Dr}$. Jain Prakash Chand, MBBS. MD. Both from the Department of paediatrics, Cantonment General Hospital, Delhi Cantt, New Delhi, 110010

\section{Address for correspondence:}

dr.sanghamitra.ray@gmail.com

\section{How to cite}

Ray S, Jain PC. Nonsyndromic Split Hand/ Foot Malformation: Ectrodactyly. J Nepal Paediatr Soc 2016;36(1):103-104.

doi: http://dx.doi.org/10.3126/jnps.v36i1.14662

This work is licensed under a Creative Commons Attribution 3.0 License.

\section{(c) (7)}

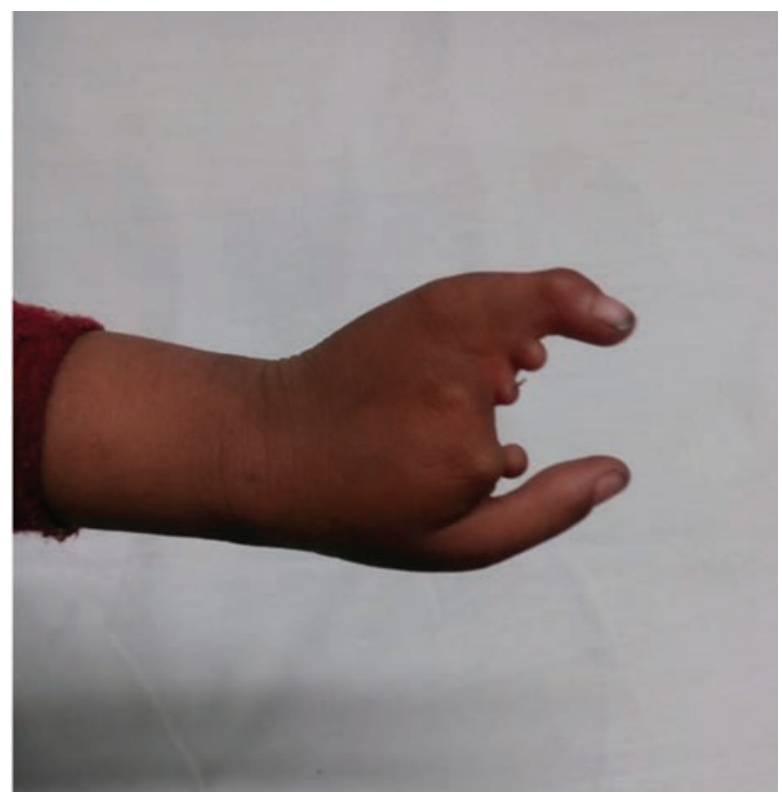

Fig 1A: Ectrodactyly

\section{The Case}

A three year old girl came to our OPD with deformity of left hand called ectrodactyly. She had no other deformities, dysmorphic features and was developmentally appropriate. The X-ray of the hand showed normal radius, ulna and metacarpals but absence of phalanges of the middle three fingers of left hand. She was examined in detail for any ectodermal anomaly, clefting of lip or palate. USG abdomen, kidney and urinary tract was done to rule out any urinary tract malformation. She was finally referred to higher centre for reconstructive surgery for ectrodactyly.

\section{Discussion}

Incidence of Split-hand/foot malformation (SHFM)/ectrodactyly, also known as "lobster claw hand," has been reported to be about 1 in 90,000 babies with no sex predilection. Two expressions of SHFM occur, one with isolated involvement of the limbs, known as the nonsyndromic form, and the second, the syndromic form 'EEC syndrome', with associated anomalies such as ectodermal and craniofacial findings, orofacial clefting ${ }^{1}$. Ectrodactyly can be treated surgically in order to improve function and appearance. Prosthetics may also be used ${ }^{2}$. Parents should be counselled regarding the possibility of recurrence of the disease.

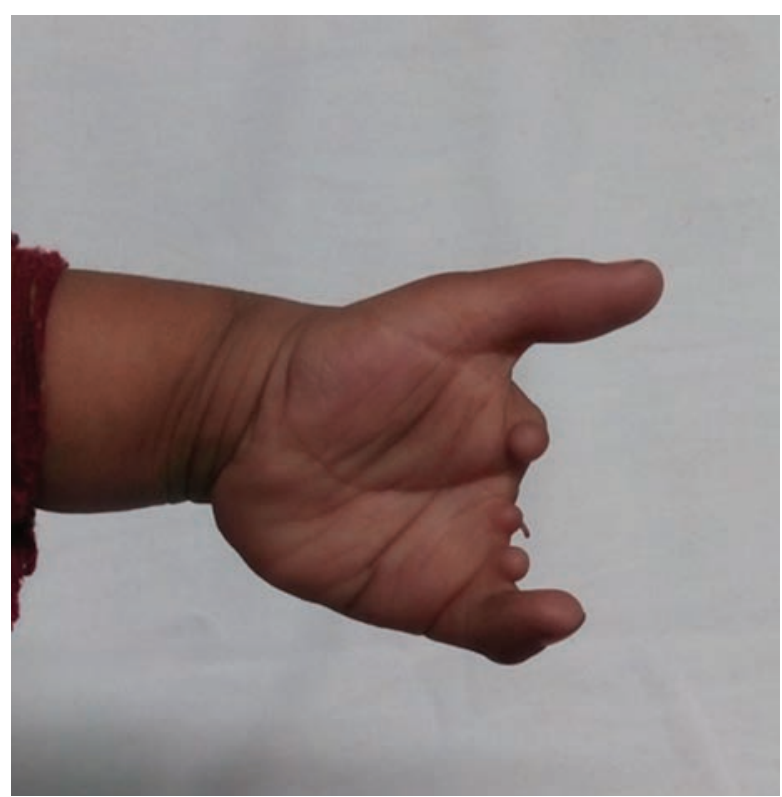

Fig 1B: Ectrodactyly 


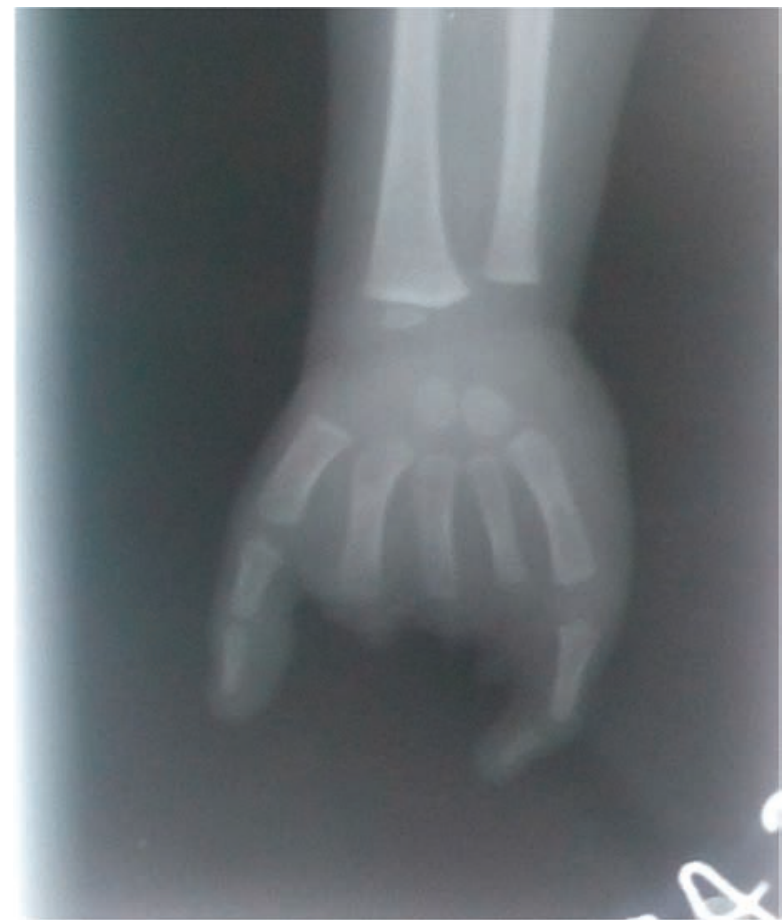

Fig 2: $X$ ray showing absence of phalanges of the middle three fingers of left hand.

\section{References}

1. Pinette M, Garcia L, Wax JR, Cartin A, Blackstone J. Familial ectrodactyly. J Ultrasound Med. 2006;25:1465-7.

2. Upton J, Taghinia AH. Correction of the typical cleft hand. J Hand Surg Am 2010;35:480-5. 